\title{
Alternate Neuromuscular Target Selection following the Loss of Single Muscle Fibers in Drosophila
}

\author{
Sydney Cash, ${ }^{a}$ Akira Chiba, and Haig Keshishian \\ Department of Biology, Yale University, New Haven, Connecticut 06511
}

The Drosophila embryonic and larval body wall consists of a simple array of segmental muscle fibers, innervated in a precise manner by identified neurons. During development motoneurons were forced to find alternate targets following the selective deletion of a single muscle fiber, the pleural internal oblique \#5. We used backfills, intracellular dyefills, and immunocytochemistry in embryos and larvae to characterize the normal motoneurons to the fiber. Deleting the fiber using either a genetic or laser lesioning method yielded essentially the same result. In nearly half the cases examined, an ectopically placed neuromuscular projection was found on either of two neighboring muscle fibers, with one favored eight times more than the other. The ectopic projection derived from the nerve branch that normally supplied the deleted muscle fiber 5 . Motoneuronal endings on undeleted muscle fibers elsewhere in the body wall had normal morphology. The ectopically placed motor terminals accumulated glutamate in normally sized synaptic boutons, beneath which transmitter sensitivity was localized. The number of boutons and branches at the ectopic endings did not differ significantly from those on intact muscle fiber 5s. Also, the native motoneurons did not alter their arborization sizes in response to a supernumerary ectopically placed contact. While the orientation of the individual ectopically placed branches was variable, the ectopic endings occupied a predictable site on the surrogate muscle fibers. The results suggest that Drosophila motoneurons can project to body wall destinations in the absence of their muscle fiber targets, and that alternate muscle fibers are selected by their proximity. The muscle fibers will support apparently stable and functional supernumerary motor endings on ectopic sites, and these inputs do not significantly influence the behavior of the native motoneurons. The data suggest that Drosophila motoneurons may behave autonomously when making synapses, and that competition does not play a major role in the matching of motoneuron to muscle fiber.

The innervation of the body wall musculature of Drosophila embryos and larvae is highly stereotyped, permitting the identification of both individual muscle fibers and their innervating

\footnotetext{
Received Oct. 10, 1991; revised Dec. 17, 1991; accepted Dec. 23, 1991.

We thank Robert Wyman and Elizabeth Harkins for comments on the text, and Douglas Kankel for discussion of the data. This work was supported by grants from the NIH and March of Dimes Birth Defects Foundation to H.K.

Correspondence should be addressed to Haig Keshishian, Department of Biology, Yale University, P.O. Box 6666 KBT, New Haven, CT 06511.

" Present address: Columbia University School of Medicine, New York, NY 10032.

Copyright (C) 1992 Society for Neuroscience $0270-6474 / 92 / 122051-14 \$ 05.00 / 0$
}

motoneurons (Johansen et al., 1989 a,b; Halpern et al., 1991; Sink and Whitington, 1991 a). In wild-type embryos and larvae, the connectivity between each motoneuron and muscle fiber is precise (Halpern et al., 1991; Sink and Whitington, 1991a), raising the possibility that innervating motoneurons are capable of distinguishing individual muscle fibers during their initial neurite outgrowth and synaptic development. The cellular mechanisms that generate ncuromuscular specificity in Drosophila are beginning to be understood. Sink and Whitington (1991b) have reported that some motoneuronal processes that contact incorrect muscle fibers are withdrawn as development progresses. Halpern et al. (1991) have found that specific embryonic muscle fibers are labeled by cell surface glycoproteins that have been shown to function as cell adhesion molecules in vitro, and that these proteins are coexpressed by specific preand postsynaptic partners during synaptogenesis.

These observations, based on the behavior of motoneurons during normal development, make it desirable to test the effects of manipulations of either the motoneurons or muscle fibers. In this study, we have used both genetic and laser lesioning techniques to delete single muscle fibers in order to deny motoneurons their normal targets. When a single muscle fiber was deleted using either method, we observed apparently functional but ectopically placed motor endings on neighboring musclc fibers. The ectopic neuromuscular endings did not affect the morphology or placement of the native ending. The ectopically placed contacts on the alternate targets were located a short distance from where synapses would have been made on the deleted muscle fiber. The results show that motoneurons can grow to specific regions of the body wall in the absence of their targets, and that the path a motoneuron takes in the periphery can be important in determining where on a muscle fiber the neuromuscular endings will be located. Furthermore, these data indicate that competitive mechanisms are not predominant in determining either target choice or synaptic location and morphology.

Some of these results were presented in abstract form (Cash and Keshishian, 1990).

\section{Materials and Methods}

Drosophila stocks. Wild-type Canton S Drosophila melanogaster were maintained at room temperature in uncrowded bottles. Embryos were collected on yeasted apple juice-agar plates from population cages as previously described (Halpern et al., 1991). Homeotically transformed larvae with the $a b x p b x b x^{3} / D f(3 R) P 2$ genotype were obtained by crossing $a b x p b x b x^{3} / D p(3 R) P 5, T b, S b$ with $D f(3 R) P 2 / D p(3 R) P 5, T b, S b$ parent stocks. Homeotically transformed larvae in this cross are wild-type for the Tubby and Siubble genes and thus have normal body size.

In addition to monitoring the Tubby phenotype, several criteria were used to ensure that the larvae examined were of the desired genotype. 

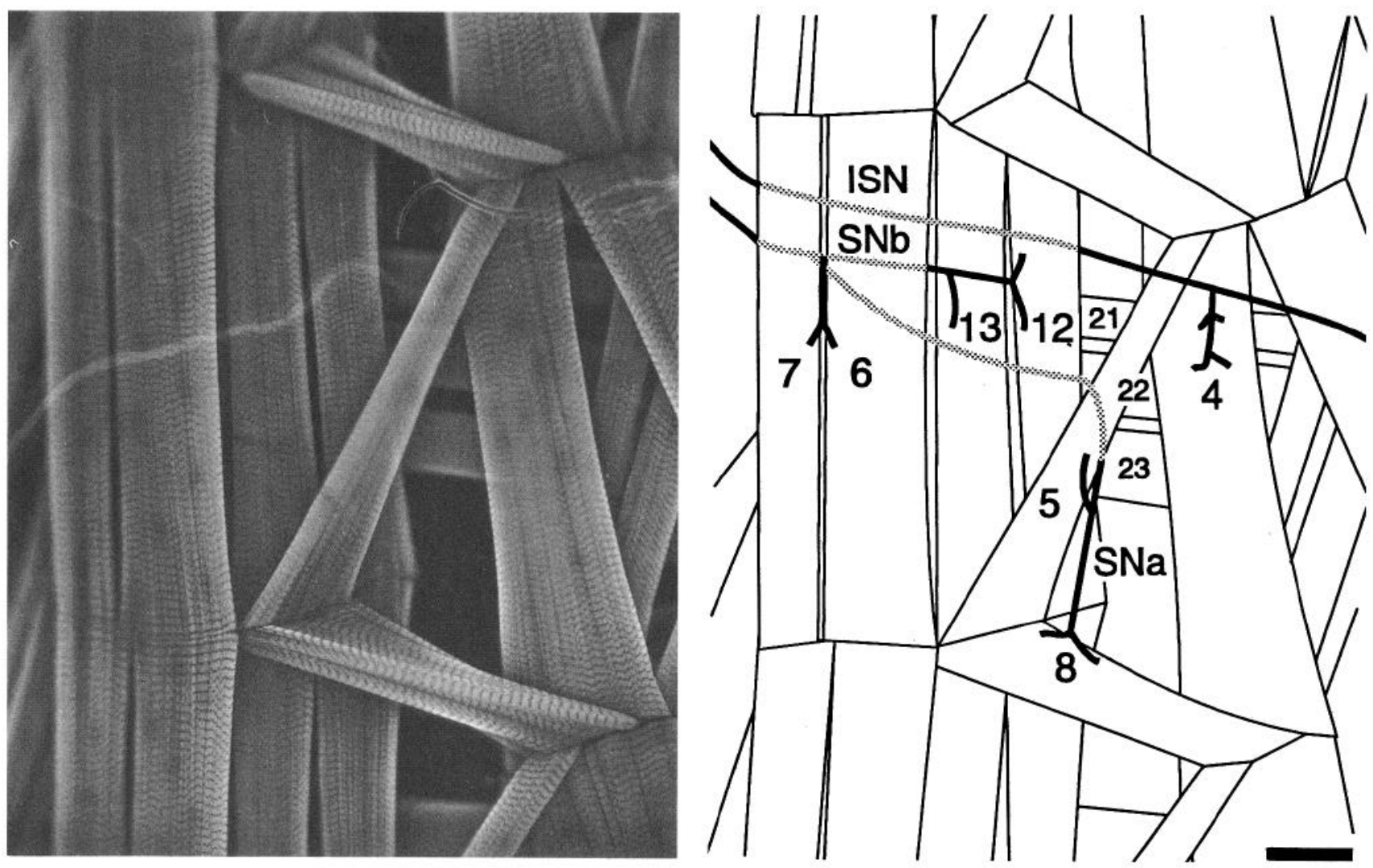

Figure 1. The ventral muscle fibers of a single abdominal hemisegment (A3) are shown fluorescently labeled with rhodamine phalloidin in the left panel. The right panel shows a schematic diagram of the ventral internal and external muscle fibers and the major nerve branches. In this and all subsequent figures, anterior is to the top and the ventral midline is to the left. The nerves drawn crosshatched project on the external side of the muscle fibers. $I S N$, intersegmental nerve; $S N a, S N b$, segmental nerve branches a and b. Scale bar, $50 \mu \mathrm{m}$.

Pupae from the cross were dissected and examined for the presence of four instead of two developing wings. This established the effectiveness of the cross in general. Furthermore, when dissected, individual larvae were checked for the presence of duplicated wing imaginal disks. These large imaginal disks are easily located and distinguished in the larval body wall. Only individuals with such a duplication were used for dissections. These checks, along with phenotypic markers on the parent stocks, ensured that all individuals used in the study were of the correct genotype.

Neuronal labeling. Crawling third instar larvae were filleted and immunolabeled with anti-HRP (which labels all central and peripheral neurons in Drosophila; Jan and Jan, 1982) and anti-glutamate sera as previously described Johansen et al., 1989a, b). Enhanced video images of both fluorescence- and diaminobenzidine-immunolabeled body walls were collected as previously described (Halpern et al., 1991). Glutamate iontophoresis and Lucifer yellow dyefills were performed as previously described (Johansen et al., 1989a; Halpern et al., 1991).

Backfills. The lipophilic dyes $1,1^{\prime}$-dioctodecyl-3,3,3',3'-tetramethylindocarbocyanine perchlorate (DiI) and 1, $1^{\prime}$-dioctodecyl-3,3,3', $3^{\prime}$-tetramethyloxycarbocyanine perchlorate $(\mathrm{DiO})$ were used to label muscle fibers specifically and to backfill innervating motoneurons in paraformaldehyde-fixed late stage 16 embryonic body wall fillets (staging scheme of Campos-Ortega and Hartenstein, 1985). The fillets were dissected and fixed as described by Halpern et al. (1991). A solution of $10 \%$ dye in a blend of 1:9 dimethyl sulfoxide: ethanol was used. The dye solution was applied by pulsed pressure ejection from a micropipette broken near its tip and touched to individual muscle fibers. After application, the dye was allowed to backfill the neurons for up to $1 \mathrm{~d}$ at $4^{\circ} \mathrm{C}$. Fluorescently backfilled cells were imaged using a Bio-Rad MRC 500 confocal microscope.

Laser lesioning. The laser lesioning of muscle fiber 5 was done in stage 15-16 embryos, a time when the musculature is visible but has not yet become innervated (Johansen et al., 1989b). The embryos were manually dechorionated on double-stick tape and immersed in halo- carbon 700 oil beneath a coverslip. Muscle fiber 5 was identified through the vitelline membrane using Nomarski optics and video-enhanced imaging. The muscle fiber was lesioned by directing a series of $3 \mathrm{nsec}$ laser pulses with a peak power of $5-8 \mathrm{~kW}$ at $440 \mathrm{~nm}$, generated by an LSI VSL 337 dye laser and a dual mirror dye cell with coumarin 440 laser dye. The laser light was focused with a $75 \mathrm{~mm}$ planoconvex lens and directed through the lamp port of a Zeiss IV FL fluorescence epiiluminator. The light was reflected with a $510 \mathrm{~nm}$ dichroic mirror oriented at $45^{\circ}$ to a 1.4 NA $63 \times$ planapochromatic objective, resulting in an approximately $2 \mu \mathrm{m}$ spot. This arrangement permitted efficient laser illumination while the preparation was monitored with a Newvicon video camera and Nomarski optics. After muscle fibers were lesioned, the embryos were transferred to small Petri dishes with food and allowed to develop at room temperature to the third instar.

\section{Results}

Muscle pattern and nerve branch anatomy in wild-type larvae The anatomy and innervation of the muscle fibers discussed in this article are illustrated in Figure 1. In the left panel, the musculature of a third instar larva is shown labeled with rhodamine phalloidin, which stains actin filaments. The identifying muscle numbers (Crossley, 1978) and the innervating nerves are shown schematically in the right panel. Each fiber is a multinucleate cell, singly identifiable by its position, orientation, size, and site of insertion on the body wall (Johansen et al., 1989a). The muscle fibers are innervated by branches of the segmental (SN) and intersegmental (ISN) nerves. Muscle fibers $7,6,13$, and 12 are each innervated by the $\mathrm{SNb}$ branch, whereas muscle fibers 5 and 8 receive their innervation via the $\mathrm{SNa}$ 

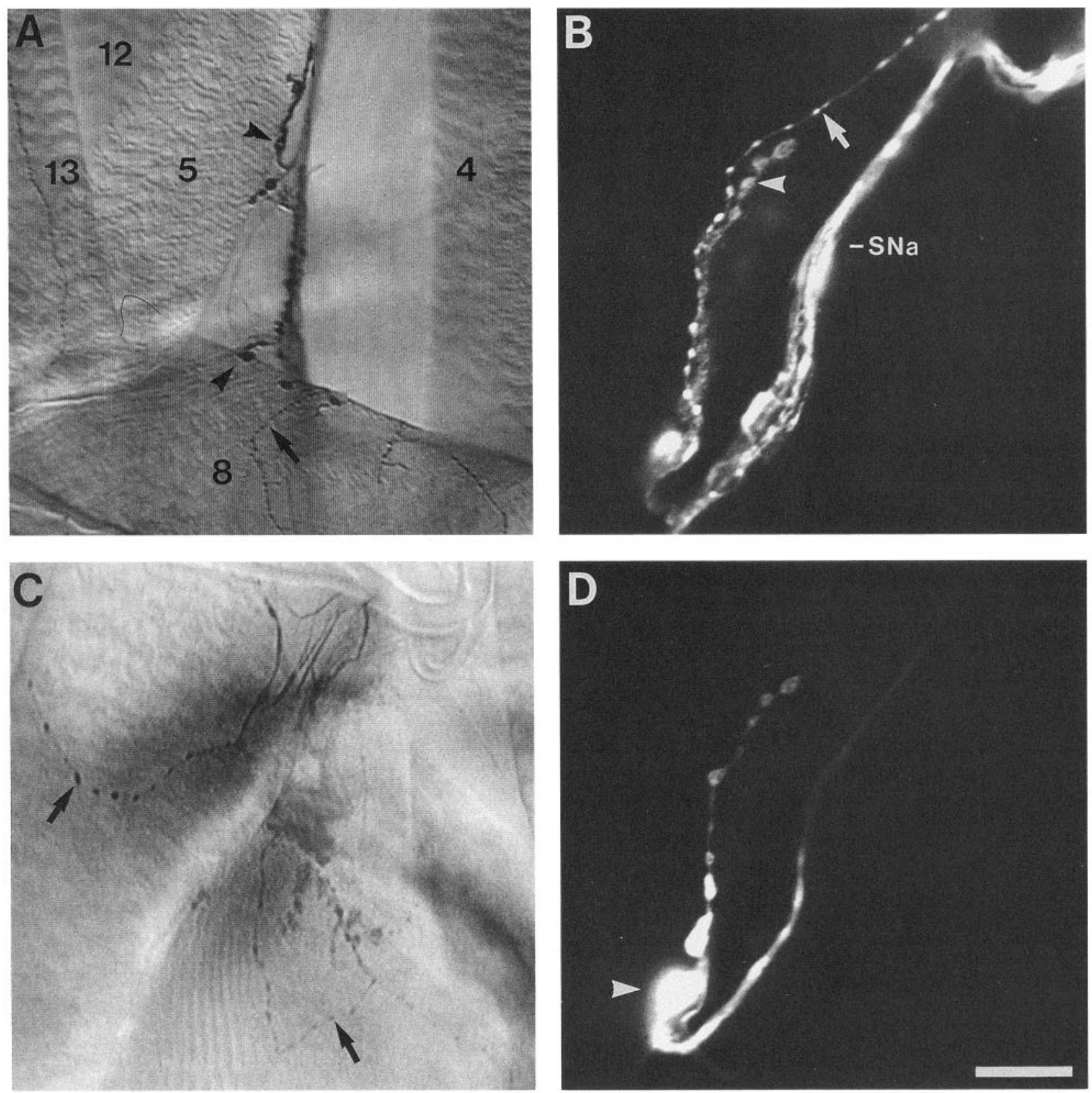

Figure 2. The innervation of muscle fibers 5 and 8 , revealed with neuron-specific immunocytochemistry and by intracellular dyefills of neuromuscular arborizations. $A$, The neuromuscular junctions of muscle fibers 5 and 8 in segment A5, labeled with anti-HRP immunocytochemistry and peroxidase reaction. In segments posterior to A3, muscle fiber 5 is innervated exclusively by type I (large-bouton, top arrowhead) endings (the segment-specific distribution is shown in Fig. 7 C). Muscle fiber 8 has mixed type I (lower arrowhead) and type II (small-bouton, arrow) innervation in all abdominal segments. $B$, Neuromuscular endings on muscle fiber 5 in segment A3, shown here with anti-HRP immunofluorescence. This muscle fiber has the mixed type I and type II endings often seen in segments A1-A3. $C$ and $D$, Type I and II processes are from different neurons. $C$, In this negative fluorescence image, a single motoneuron bouton was impaled and dyefilled with Lucifer yellow in segment A1. The dyefill reveals type II processes arborizing over both muscle fibers (arrows). Note that no type I processes were dyefilled. $D$, A single bouton (arrowhead) from one of the motoneuronal processes shown in $B$ was impaled and the motoneuron dyefilled with Lucifer yellow, revealing a single anteriorly directed process with type I morphology only. The type II process visible with anti-HRP immunocytochemistry in $B$ is therefore from a second motoneuron. SNa, segmental nerve a branch. Scale bar: $A, 20 \mu \mathrm{m} ; B, 16 \mu \mathrm{m} ; C$ and $D, 15 \mu \mathrm{m}$.

branch. Muscle fiber 4 and other dorsal muscle fibers are innervated by branches of the ISN (Johansen et al., 1989a).

Anatomy of neuromuscular endings on muscle fibers 5 and 8 in wild-type larvae

As the bithorax mutation used in this study deletes muscle fiber 5 , and to a lesser extent muscle fiber 8 in anterior segments
(Hooper, 1986), we chose to examine the innervation of those muscle fibers in detail. In wild-type larvae, muscle fiber 5 spans the segment obliquely in the internal layer of ventral muscle fibers. The muscle fiber is present in abdominal segments A1A7. It inserts its posterior end on the body wall at the segment border, on the same site as muscle fiber 13. At its anterior end, it inserts at the segment border at the same site as muscle fiber 

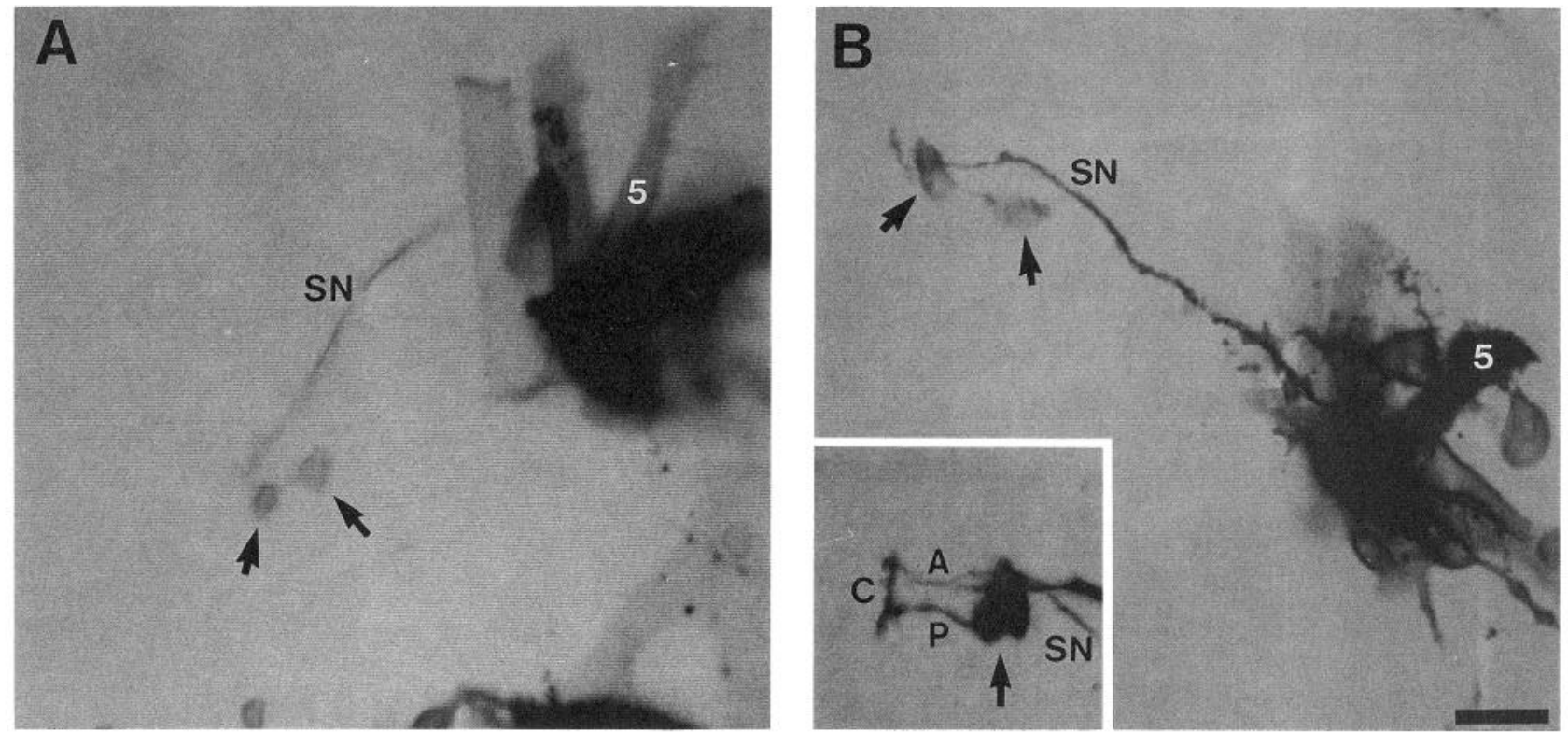

Figure 3. Fluorescence backfills of motoneurons to muscle fibers 5 and 8 in stage 16 embryos. $A$ and $B$, DiI backfills comparing motoneurons to muscle fibers 5 and 8 in either anterior $(A)$ or posterior $(B)$ body wall segments. In $A$, two cell bodies were revealed (arrows) whose axons exit ipsilaterally in the same CNS segment as the muscle fibers. In $B$, three cell bodies are revealed (arrows), with axons also exiting ipsilaterally in the same segment as the muscle fibers. The inset shows the CNS trajectory followed by the dyefilled neurons of a third preparation. The axons project medially along the posterior commissure $(P)$ to the ipsilateral connective $(C)$, turn anteriorly to contact the anterior commissure $(A)$, and exit the CNS via the SN. Negative images of fluorescence using laser confocal microscopy. Scale bar, $10 \mu \mathrm{m}$.

4. Muscle fiber 8 is oriented transversely along the posterior segment border. Its medial end inserts onto the same body wall site as muscle fibers 5 and 13. Its lateral end inserts at the posterior insertion site of muscle fiber 4 , where it is also contacted by the anterior end of the muscle fiber 5 from the next posterior segment (Fig. 1).

Muscle fibers 5 and 8 as well as the transverse muscle fibers 21-24 are innervated by branches of $\mathrm{SNa}$. Near the lateral edge of muscle fiber 12, SNa divides into several terminal branches. One set of nerve branches (not shown in Fig. 1) terminates on the superficial transverse muscle fibers $21-24$, which lie directly external to muscle fibers 12,5 , and 4 . A single posterior branch crosses the external side of muscle 5 and divides to innervate muscle fibers 5 and 8 . This nerve branch also carries axons of afferent neurons.

In wild-type larvae, the neuromuscular ending on muscle fiber 5 is always located on the side facing the dorsal midline (hereafter termed the lateral edge) and usually consists of up to two short (approximately $50 \mu \mathrm{m}$ ) processes that can run in both anterior and posterior directions from the nerve entry point (Fig. $2 A$, top arrowhead). Neuromuscular endings in Drosophila larvae are classified into either type I processes with large boutons or fine type II processes with boutons smaller than $1 \mu \mathrm{m}$ (Johansen et al., 1989a; Budnik et al., 1990). Type I endings are always present on muscle fiber 5 . The type II endings are found in a subset of the muscle fiber $5 \mathrm{~s}$ in segments $\mathrm{A} 1-\mathrm{A} 3$ (Fig. $2 B$, arrow) and are never observed in more posterior segments (see also Fig. $7 \mathrm{C}$ ). Dyefills indicate that these two classes of motor endings on muscle fiber 5 originate from separate motoneurons (see below).

The neuromuscular endings on muscle 8 are located on the anterior edge near the medial insertion site of the fiber. The innervation usually consists of two or more type I branches emerging from the nerve entry point (lower arrowhead, Fig. 2A) as well as finer type II processes that can project over most of the fiber's surface (arrow, Fig. 2A). Unlike the endings on muscle fiber 5, both type I and II processes are present on muscle fiber 8 in all abdominal segments.

\section{Intracellular dyefills of muscle fiber 5 and 8 neuromuscular endings}

It is possible to dyefill single motoneuronal arborizations intracellularly on larval Drosophila muscle fibers by impaling either the axon near the nerve entry point or a synaptic bouton. This technique, combined with neuron-specific antibody staining, allowed us to identify the number and branching behavior of the muscle fiber 5 and 8 motoneurons.

Figure $2 C$ shows the negative image of a single motoneuron dyefilled with Lucifer yellow following axonal impalement. The motoneuron projected over both muscle fibers 5 and 8 in segment Al and consisted exclusively of type II boutons. This indicates that the type II processes observed on muscle fiber 8 can coinnervate muscle fiber 5 ( $n=2$ dyefills). Figure $2 D$ shows a dyefill of a large-bouton type I motoneuron projecting to muscle fiber 5 in segment A3. This motoneuron was dyefilled by impaling a single bouton (arrowhead). In Figure $2 B$, the same dyefilled ending is visualized using neuron-specific immunocytochemistry, to reveal all the motoneuronal processes on the muscle fiber. In Figure $2 B$, a type II process is revealed that is distinct from the dyefilled type I ending seen in Figure 2, $B$ and $D$. This indicates that for muscle fiber 5 there are probably only two motoneurons, corresponding to the type I and II processes. In our dyefills of the large-bouton type I motoneurons all ( $n=$ $5)$ were restricted to muscle fiber 5 . Thus, muscle fiber 5 is probably innervated by two motoneurons in anterior segments, with the large-bouton motoneuron specific to fiber 5 and the small-bouton motoneuron capable of jointly innervating muscle fibers 5 and 8 . 

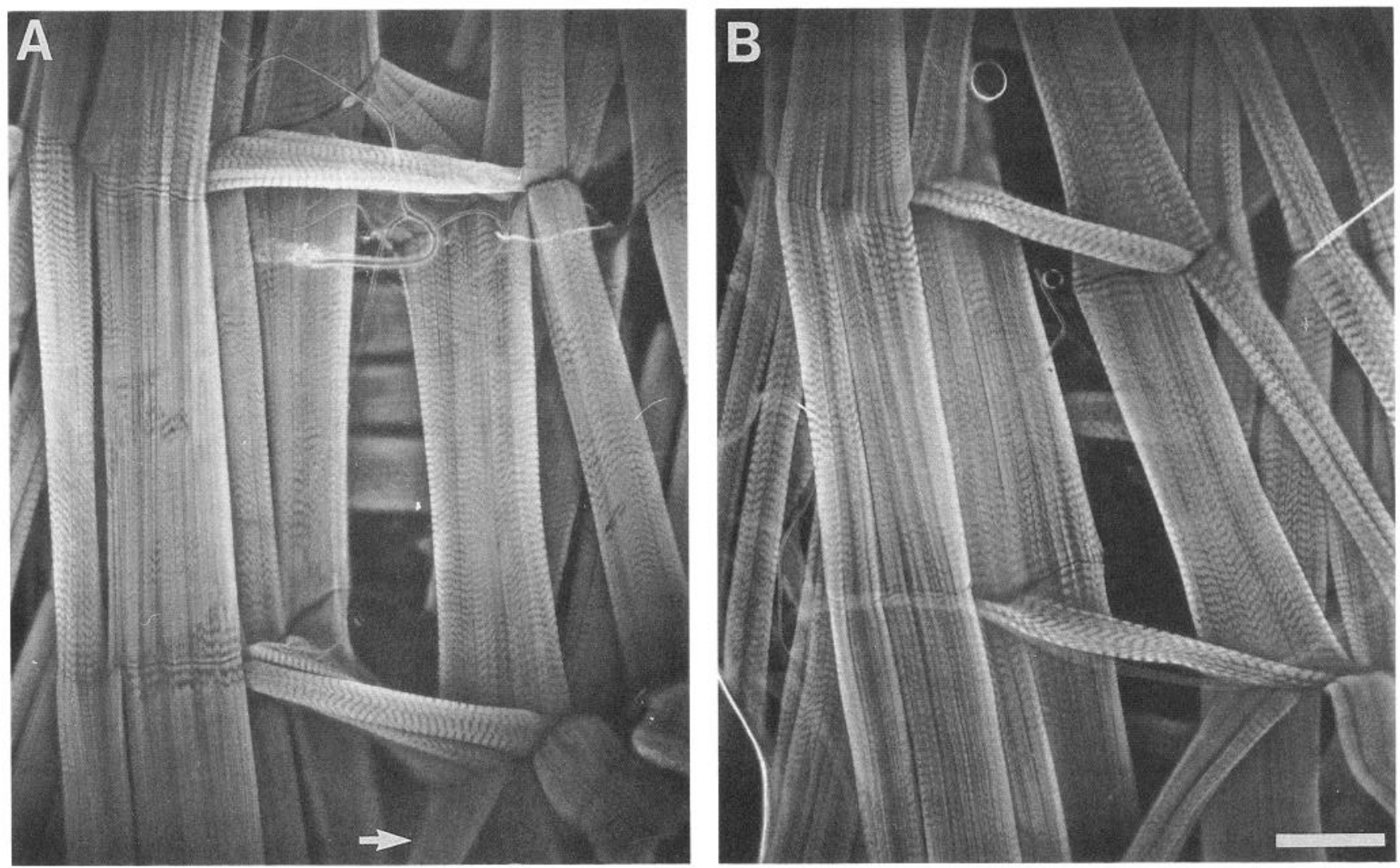

Figure 4. Deletion of muscle fiber 5 by both homeotic transformation $(A)$ and laser lesioning $(B)$. $A$, Segment $\mathrm{A} 2$ of the bithorax larva. Note the absence of muscle fiber 5 in this segment and the next anterior hemisegment (compare to Fig. 1), but not in the next posterior hemisegment (arrow). $B$, Laser lesioning of muscle fiber 5 in segment A6 during stage 15 of embryogenesis results in the permanent loss of the muscle fiber (here seen in a third instar larva). Note that in this example two of the transverse muscle fibers ( 21 and 23 ) were also lesioned. Rhodamine phalloidin labeling. Scale bar, $50 \mu \mathrm{m}$.

The CNS location of motoneurons projecting to muscle fibers 5 and 8

We used backfills with the lipophilic dyes DiI and DiO in embryos to identify the cell body locations of the motoneurons projecting to muscle fibers 5 and 8 . Dye was applied to both muscle fibers in late stage 16 embryos. This method identified clusters of up to four cells, lying in the same segment and ipsilateral to the labeled muscle fibers (Fig. 3). The backfilled cell bodies are positioned stereotypically on the dorsal aspect of the $\mathrm{CNS}$ and are ventral to the superficial "U" neurons (Thomas et al., 1984; Sink and Whitington, 1991a). The neurites project in the CNS medially from their cell bodies to the ipsilateral connective, and from there loop anteriorly, exiting the CNS via the $\mathrm{SNa}$ branch of the segmental nerve (Fig. $3 B$, inset). We observed homologous cell body positions for the neurons when backfilled from muscle fibers in either anterior or posterior abdominal segments (Fig. $3 A, B ; n=11$ ). Thus, unlike motoneurons projecting to the ventral longitudinal muscle fibers, which have cell bodies located contralateral and one segment anterior to their targets (e.g., RP1, RP3, and RP4; Halpern et al., 1991; Sink and Whitington, 1991a), the motoneurons to muscle fibers 5 and 8 reside in the same segment and project ipsilaterally.

\section{Muscle fiber 5 can be specifically deleted}

Homeosis. As there is no muscle fiber 5 in the thoracic segments, homeotic transformations resulting from mutations in the bi-

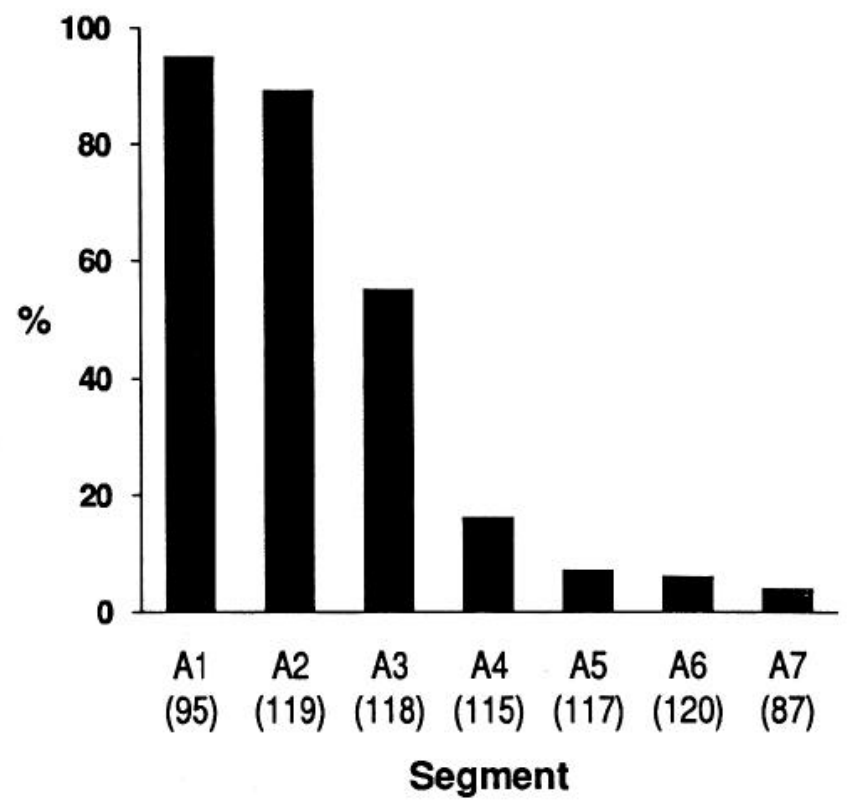

Figure 5. The observed frequency of loss of muscle 5 in abdominal segments of homeotically transformed larvae. The number of hemisegments examined in each segment is shown in parentheses. The data are based on a total of 771 bithorax hemisegments. 
Table 1. Distribution of ectopically placed neuromuscular endings in third instar bithorax hemisegments missing muscle fiber 5

\begin{tabular}{|c|c|c|c|c|c|}
\hline \multirow[b]{2}{*}{ Result } & \multicolumn{5}{|c|}{ Hemisegment $^{a}$} \\
\hline & $\begin{array}{l}\text { A1 } \\
(62)\end{array}$ & $\begin{array}{l}\text { A2 } \\
(94) \\
\end{array}$ & $\begin{array}{l}\text { A3 } \\
(60) \\
\end{array}$ & $\begin{array}{l}\text { A4 } \\
(12) \\
\end{array}$ & $\begin{array}{l}\mathrm{A} 1-\mathrm{A} 4 \\
(228)\end{array}$ \\
\hline Ectopic synapses on musclc fiber 12 & $20 \%$ & $49 \%$ & $38 \%$ & $33 \%$ & $37 \%$ \\
\hline Ectopic synapses on muscle fiber 4 & $6 \%$ & $4 \%$ & $3 \%$ & $0 \%$ & $4 \%$ \\
\hline Fstopic synapses on external side of 12 and 13 & $6 \%$ & $3 \%$ & $2 \%$ & $0 \%$ & $3 \%$ \\
\hline $\mathrm{SNa}$ branch to muscle fibers 5 and 8 lost & $45 \%$ & $26 \%$ & $3 \%$ & $8 \%$ & $24 \%$ \\
\hline No ectopic synapses detected, $\mathrm{SNa}$ intact & $19 \%$ & $16 \%$ & $52 \%$ & $58 \%$ & $29 \%$ \\
\hline Unclassifiable & $3 \%$ & $2 \%$ & $2 \%$ & $0 \%$ & $2 \%$ \\
\hline
\end{tabular}

a The total number of hemisegments examined is indicated in parentheses.

thorax complex (BX-C), as observed in the $a b x p b x b x^{3} / D f(3 R) P 2$ genotype, result in the fiber's loss in affected abdominal segments (Hooper, 1986). Figure $4 A$ shows an example of an A2 hemisegment in a homeotically transformed third instar larva where muscle fiber 5 is absent. Each of the muscle fibers normally found in this region of the body wall, with the exception of muscle fiber 5 , is present and has normal wild-type anatomy. As these apparently unaffected muscle fibers have thoracic counterparts, it is not possible to state whether they too have been transformed. Despite segmental transformation, the fibers are innervated by motor endings that appear unaltered, as determined by neuron-specific immunocytochemistry. The endings on these fibers (data not presented here) have the same morphology, site of innervation, and branch structure as described for the wild-type by both Johansen et al. (1989a) and Budnik et al. (1990).

The loss of muscle fiber 5 due to homeosis is segment specific. Figure 5 shows the fraction of 771 larval hemisegments where muscle fiber 5 was absent. Greater than $90 \%$ of the hemisegments examined in $\mathrm{A} 1$ and $\mathrm{A} 2$ were missing the muscle fiber. The frequency of fiber loss falls to about $50 \%$ in segment A3 and was less than $20 \%$ in posterior segments. Thus, as first reported by Hooper (1986), the distribution of fiber transformations in this genetic background is multisegmental and principally in the anterior abdominal region.

Laser ablation. Muscle fiber 5 was deleted in wild-type larvae by means of laser ablation in stage 15-16 embryos. At this stage of embryogenesis, motor endings have not yet been made on the muscle fibers (Johansen et al., 1989b). Figure $4 B$ shows a rhodamine phalloidin-labeled third instar A6 hemisegment where muscle fibers 5,21 , and 23 were deleted in this fashion. A set of larvae $(n=15)$ was generated with only muscle fiber 5 deleted and was used for the purpose of phenocopying the bithorax loss of muscle fiber 5 .

\section{Effects of homeosis}

CNS. Homeosis due to loss of function within the Ubx domain of the bithorax complex generally causes transformation of the metathoracic segment toward the mesothorax in ectodermally derived tissues (Lewis, 1978). There is evidence, however, that some structures (e.g., "lateral dots") may be transformed in the abdominal CNS in Drosophila hemizygous for the Ubx region (Ghysen and Lewis, 1986). We examined whether there were transformations in the CNS that could potentially affect the motoneurons innervating muscle fibers 5 and 8 . In particular, as the muscle fibers are innervated by neurons in their own segment (Fig. 3), we were concerned whether thoracic neuronal phenotypes could be observed in the abdominal segments of homeotically transformed larvae. To test this, we examined the distribution of neurons with small cardioactive peptide $b(\mathrm{SCPb})$ immunoreactivity. A single pair of SCPb-like immunoreactive neurons is present in each thoracic segment of embryos and larvae, with no cell body immunoreactivity in any of the abdominal segments (Masinovsky et al., 1988). We examined the pattern of immunoreactivity in the ganglia of bithorax third instar larvae. In no case ( $n=12$ ganglia) were $\mathrm{SCPb}$-immunoreactive cells found in the abdominal segments (data not shown). This indicates that if there was any homeotic transformation of the abdominal CNS it was partial.

Neuromuscular effects. We next examined the anatomy of the neuromuscular endings present on each of the ventral and pleural body wall muscle fibers of abdominal segments in the homeotically transformed larvae. We noted no consistent aberrations in ending anatomy on the muscle fibers, except for the presence of an ectopically placed ending on either muscle fiber 12 or 4 . The presence of an ectopic ending on muscle fiber 12 or 4 depends on the loss of muscle fiber 5 in that hemisegment. In 228 hemisegments from A1 through A4 where muscle fiber 5 was missing, 95 ectopic endings were detected on the internal facing side of either muscle fiber 12 or 4 , representing a frequency of $37 \%$ on muscle fiber 12 and $4 \%$ on muscle fiber 4 (Fig. 6A,B). In a further eight cases (3\%), an ectopically placed ending was observed on the external facing side of either muscle fiber 12 or 13, a location where neuromuscular endings are not found in wild-type (Johansen et al., 1989a). By contrast, in 465 hemisegments examined with an intact muscle fiber 5 in this genetic background, only 9 cases (1.9\%) were found to an ectopically placed ending on adjacent fibers. We did not observe ectopic endings simultaneously on both muscle fibers 12 and 4 when muscle fiber 5 was absent. Also, for a sample of $98 \mathrm{hcmi-}$ segments located between segments $\mathrm{A} 1$ and $\mathrm{A} 4$, in no case did we observe an intact muscle fiber 5 that was not innervated.

The ectopic endings are likely the displaced motoneuron terminals that normally project to the missing muscle fiber 5 . The ectopic endings occur when muscle fiber 5 is missing and arise from the same terminal nerve branch of SNa that would have normally projected to that muscle fiber. The ectopic endings have other features that resemble the native contact on muscle fiber 5 , including bouton number, branch number, and distribution of type I and II processes (see below).

Among the hemisegments missing muscle fiber 5, where an ectopic ending was not detected, there were 55 cases $(24 \%)$ where 

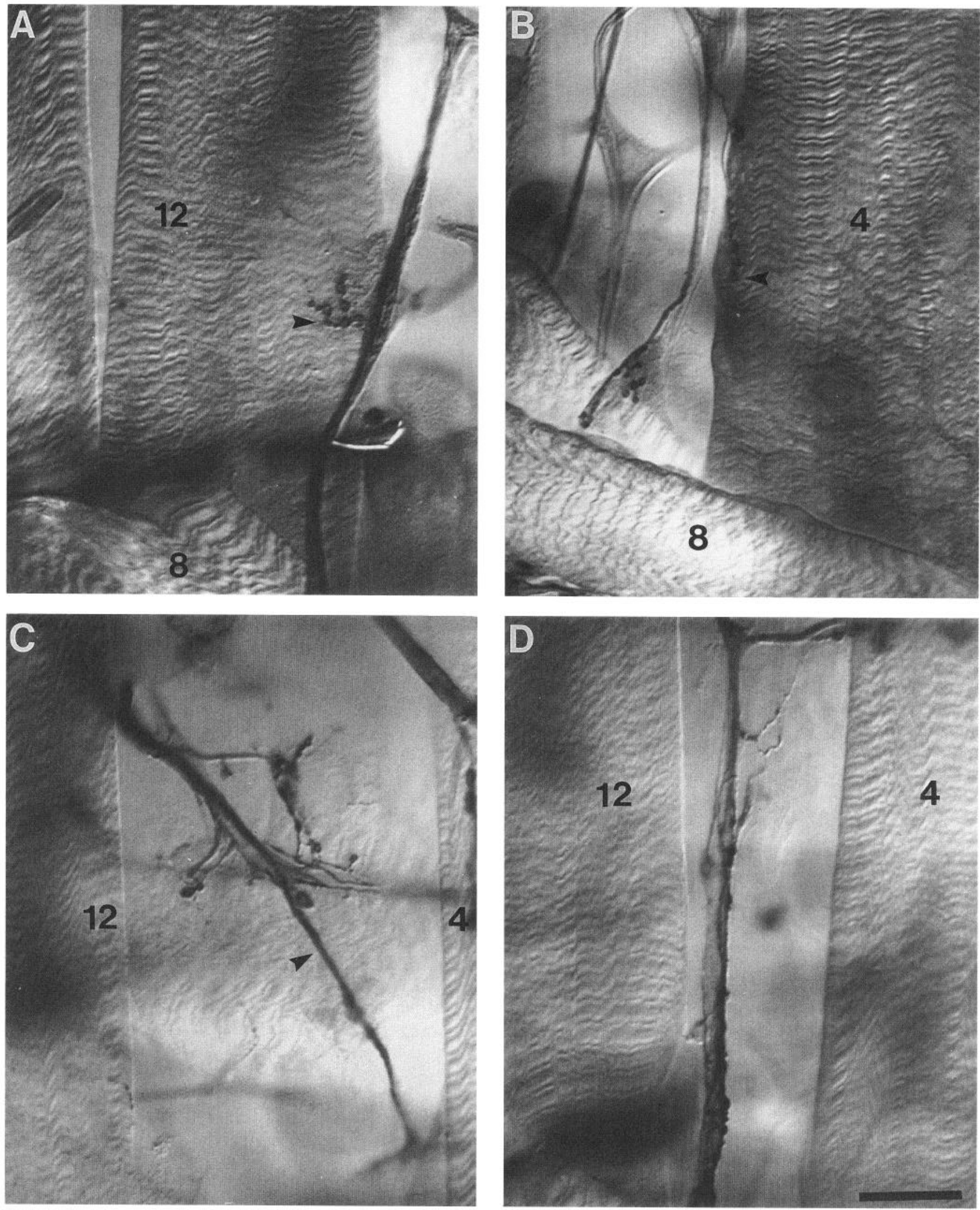

Figure 6. The ectopically placed endings and the effects upon nerve pathways observed following loss of muscle fiber 5 in homeotically transformed larvae. The four most common kinds of results are shown. A, A single ectopically placed type I ending (arrowhead) is shown located on the posteriorlateral surface of muscle fiber 12 , in segment A3. This class represented $37 \%$ of the hemisegments examined. B, A single type I ending (arrowhead) ectopically placed on the posterior-medial surface of muscle fiber 4 in segment A3. This class represented $4 \%$ of the hemisegments. $C$, The loss of the SNa nerve branch to muscle fiber 8 in A3. In this example, the muscle fiber 8 is also missing. No ectopic endings were observed for this class. The arrowhead indicates the SN branch to the transverse muscle fibers. This class represented $24 \%$ of the hemisegments. $D$, The presence of a normal SNa branch with no observed ectopic endings, shown here in segment A3. This class represented $32 \%$ of the hemisegments. Data are based on 228 hemisegments from A1 to A4. Anti-HRP immunocytochemistry with peroxidase reaction. Scale bar, $25 \mu \mathrm{m}$. 

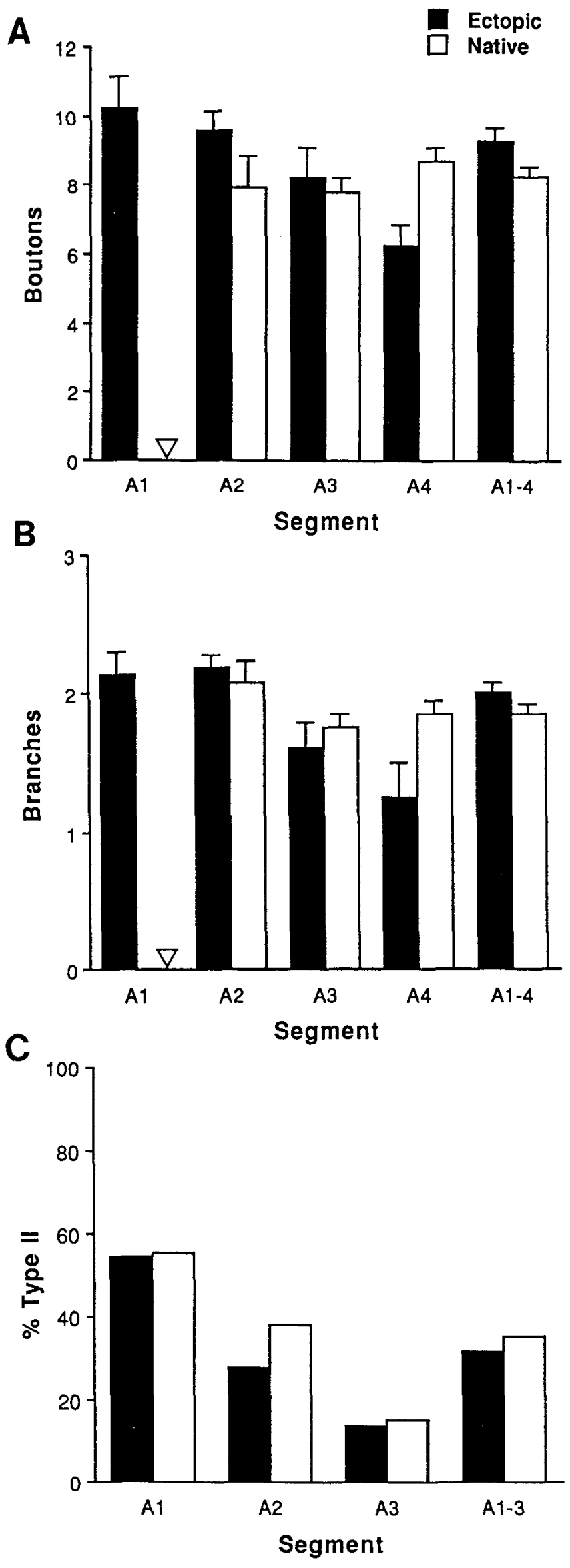

the SNa nerve branch stopped short of muscle fiber 8 . 'This invariably involved the loss of the projection to muscle fiber 8 (Fig. 6C), so that the muscle fibcr, when present, remained uninnervated. Finally, we observed 72 cases $(32 \%)$ in which no ectopic endings were detected, and where there were no apparent defects in the nerve anatomy (Fig. 6D). However, the four transverse muscle fibers $21-24$ could also potentially serve as alternate targets for displaced motoneuron terminals, as they lie in the vicinity of muscle fiber 5 . On these smaller muscle fibers, an additional input mixed in with the native endings would not be easily distinguishable using neuron-specific staining alone. Thus, the observed $46 \%$ frequency of displaced motor endings in bithorax larvae is likely an underestimate.

Far more ectopic endings were detected on muscle fiber 12 than elsewhere. Eighty-three percent of all ectopic endings detected (86 out of 103) were located on muscle fiber 12 , with only $9 \%$ on muscle fiber 4 , and $7 \%$ elsewhere. These results are summarized in Table 1.

\section{Ectopic ending anatomy}

Given the hypothesis that ectopic endings are made by motoneurons that normally innervate muscle fiber 5 , we examined the extent to which the ectopic endings resemble the native ending on muscle fiber 5 . To control for effects due to genetic background, we compared hemisegments in bithorax larvae where muscle fiber 5 was present to those where it was absent. Furthermore, the comparisons were made on a segment-specific basis, to control for segmental differences observed in the degree of terminal arborizations (Johansen et al., 1989a; Budnik et al., 1990).

Ectopic motor endings on either muscle fiber 12 or 4 were invariably located near the posterior end of the muscle fiber. On muscle fiber 12, the ectopic endings always inserted from the lateral side of the muscle, where the $\mathrm{SNa}$ branch is located (Fig. 6.1). Ectopic endings on muscle fiber 4 were always located on the medial edge of the muscle fiber, also close to the $\mathrm{SNa}$ branch (Fig. 6B). As with all normal motor endings, the ectopic endings usually innervated the surface of the muscle fiber facing the animal's interior.

Among the characteristic features of Drosophila motor endings are the numbers of boutons and branches (Johansen et al., 1989 a, Budnik et al., 1990). Figure $7, A$ and $B$, shows a comparison of these features between ectopically placed type I endings on muscle fiber 12 and the native type I endings on muscle fiber 5 in bithorax larvae. The native and ectopic endings have similar numbers of both type I boutons and branches. For all segments tested, the numbers of type I boutons and branches are not significantly different between ectopic and native endings, as determined by $t$ test.

Figure 7. A comparison of the native muscle fiber 5 endings to the ectopic endings on muscle fiber 12 of homeotically transformed larvae. $A$ and $B$ compare the number of boutons and branches of type I endings for segments A1-A3. The total number of detected intact muscle fiber $5 \mathrm{~s}$ in Al (triangle) was too small $(n=4)$ to be used for a statistical comparison; the behavior of the ectopic contact in this segment is included for the purpose of comparison to the A2 and A3 ectopic and native contacts. The sample size for $A 1: 22$ ectopic contacts; $12: 50$ ectopic, 14 native contacts; $A 3: 23$ ectopic, 48 native contacts. $C$ shows the frequency of appearance, on a segment-specific basis, of fine type II contacts. The data $(n=61)$ show the percentage of observed examples of type II endings on either muscle fiber 5 in wild-type or on muscle fiber 12 in homeotically transformed hemisegments. 

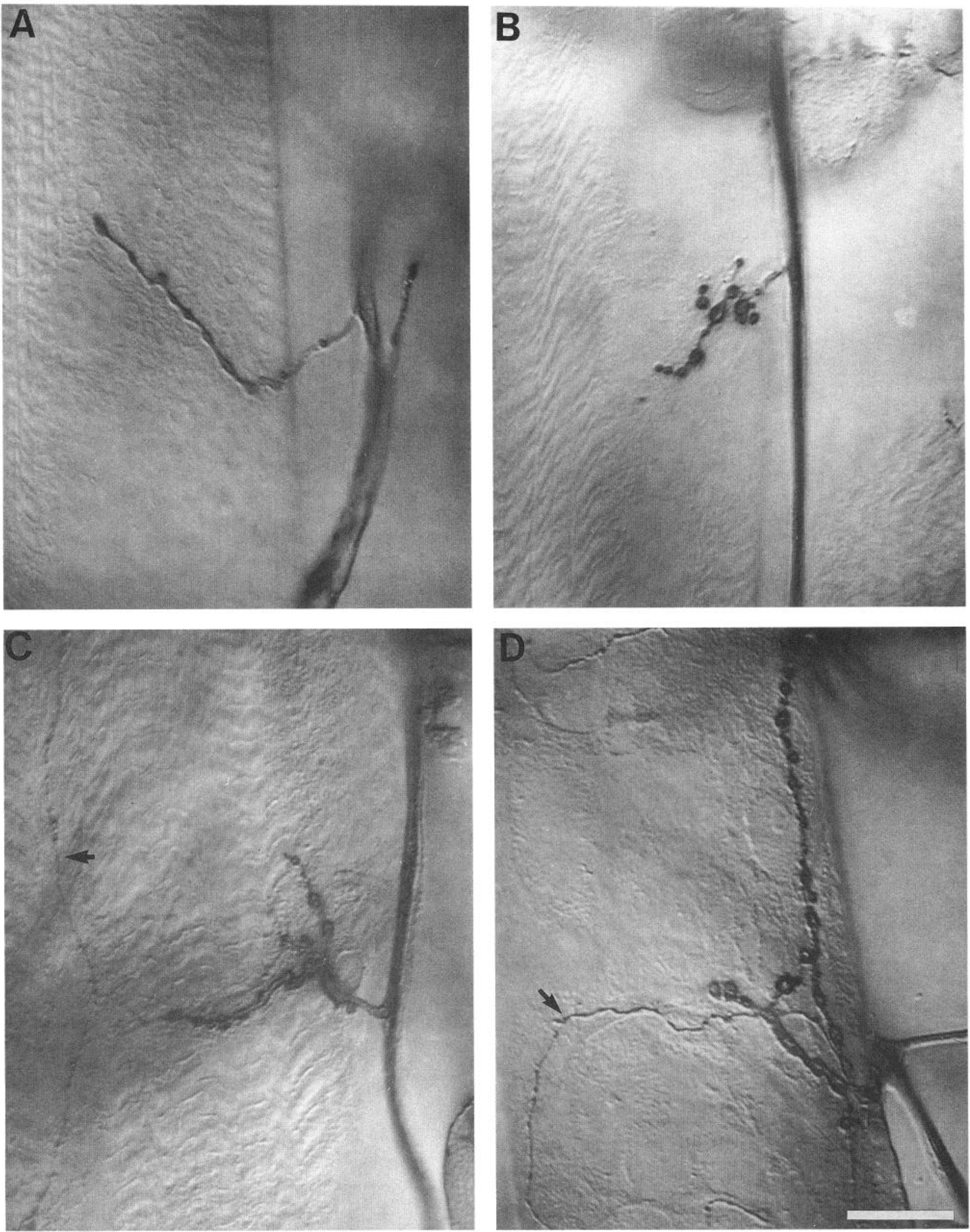

Figure 8. Variability of ectopic endings on muscle fiber 12 in homeotically transformed hemisegments lacking muscle fiber 5 . The ectopic motor endings include both the large type I and in some cases smaller type II processes, in a segment-specific distribution. $A$ and $B$ show examples of simple type I endings on the posterior-lateral surface of 12 in segments A1. In $B$, a moderately branched short type I process is shown. These endings were not accompanied by the type II process. $C$ (segment A2) and $D$ (segment A1) show examples of branched type I endings accompanied by the fine type II ending. Anti-HRP immunocytochemistry with peroxidase reaction. Scale bar, $25 \mu \mathrm{m}$. 


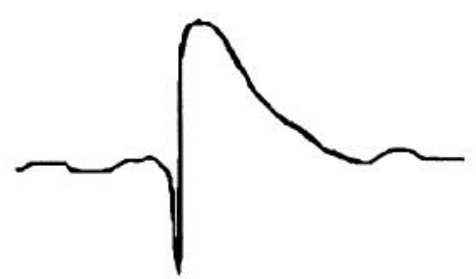

Normal Ending

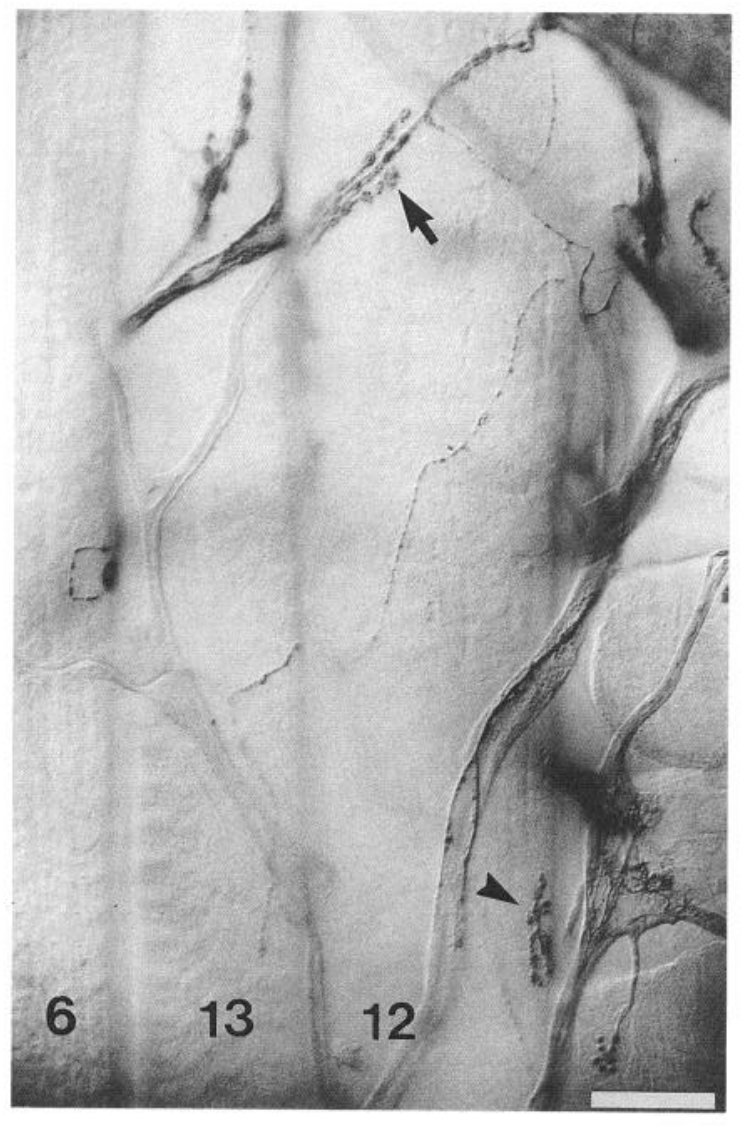

Figure 9. Intracellular potentials seen after iontophoretic application of glutamate at both normal and ectopically placed sites. The example is from a single muscle fiber 12 in a homeotically transformed hemisegment that was missing muscle fiber 5. Using video imaging and Nomarski optics to identify the motor endings in living muscle fibers, glutamate was focally applied to single boutons at the native (arrow) and ectopic (arrowhead) sites. The records show similar-sized potentials generated in response to single $1.5 \mathrm{msec}$ test pulses of $0.5 \mu \mathrm{A}$ from the iontophoresis pipette, positioned approximately $1 \mu \mathrm{m}$ above the test boutons. The live boutons were observed using Nomarski optics and video enhancement. Following fixation, the neuromuscular arborizations were labeled using anti-HRP immunocytochemistry with peroxidase reaction. Scale bar, $25 \mu \mathrm{m}$.

As noted above, a characteristic feature of the native innervation of muscle fiber 5 is the segment specific distribution of type II endings. These contacts are present on muscle fiber 5 in a subset of anterior abdominal segments. We also observed a corresponding segment specific presence of type II endings in the ectopic contacts found on muscle fiber 12 when muscle fiber 5 was absent. The frequency for which type II endings were present was similar between ectopic and normal muscle fiber 5 endings (Fig. 7C).

Despite these similarities, the ectopic muscle fiber 12 endings could differ from the native muscle fiber 5 endings in their orientation over the fiber, a feature that is normally consistent for type I arborizations (Johansen et al., 1989a). Figure 8 illustrates the variety of arborizations observed for ectopic endings on muscle fiber 12 . These ranged from lone processes emerging from the nerve entry point (Fig. $8 A$ ) to multiply branched arbors (Fig. $8 B, C$ ) whose type I processes could project over relatively long distances (Fig. 8D).

\section{Interactions between ectopic and native endings}

We next examined whether there were signs of interactions between the ectopic and native innervation on each muscle fiber 12 examined. The native ending on this fiber has been extensively described in the literature (Johansen et al., 1989a,b; Bud- nik et al., 1990) and consists of multiple branches projecting in both anterior and posterior directions from the nerve entry point at the anterior medial region of the muscle fiber. Despite the presence of foreign inputs at an ectopically placed site, the native endings on muscle fiber 12 were in general positioned in their correct location, and had their processes in the expected orientations.

In bithorax larvae, the native type I endings on muscle fiber 12 had on average $29.8 \pm 1.64$ boutons and $5.5 \pm 0.25$ branches when no ectopic endings were present. The native site had on average $33.0 \pm 2.12$ boutons and $5.9 \pm 0.36$ branches when an ectopic ending was present on the muscle fiber (mean \pm SEM; $n=48$ A $1-A 4$ hemisegments). The presence of an ectopic ending had on average no statistically significant effect on the numbers of either type I boutons or branches at the native site, as determined by $t$ test $(p>0.2)$. As a further test of correlation between the native and ectopic endings, we compared the number of boutons at native and ectopic sites on individual muscle fiber $12 \mathrm{~s}$, to see if there were any systematic trends in size between them ( $n=22$ muscle fibers). We observed no statistically significant correlation (by $F$ test; correlation coefficient $r$ $=0.041$ ). This indicates that an ectopic contact on muscle fiber 12 has neither positive nor negative influences on the size of the native ending on that muscle. 


\section{Ectopic endings are physiologically functional}

All segmental body wall motor endings in Drosophila larvae are immunoreactive for glutamate, the excitatory neurotransmitter (Johansen et al., 1989a,b). To determine whether the ectopic endings were functional, we examined both the glutamate immunoreactivity of their boutons and the responsiveness of the underlying muscle fiber membrane to iontophoretically applied glutamate. We found that the ectopic endings located on both muscle fibers 12 and 4 ( $n=7$ body walls) were immunoreactive with antibodies for the neurotransmitter glutamate, and that the endogenous endings throughout the body wall were also immunopositive.

Normally, glutamate sensitivity is found directly beneath each bouton, with low sensitivity in extrajunctional sites (Jan and Jan, 1976a,b; Johansen et al., 1989a). It is possible to recognize ectopic sites and their synaptic boutons in living body wall preparations using Nomarski optics and video imaging. Using this technique, we tested individual boutons for their responsiveness to applied glutamate ( $n=2$ body walls surveyed). Both the native and ectopic ending sites exhibited the expected physiological response (Fig. 9), with the sites beneath individual boutons exhibiting similar sensitivity to the neurotransmitter. Extrajunctional sites throughout the muscle did not show observable responses. This indicates that the ectopic endings have promoted the accumulation of glutamate sensitivity beneath their boutons in a fashion similar to native synapses.

\section{Ectopic endings arise in response to laser ablation of muscle fiber 5}

Using a laser microbeam, we phenocopied the effects of the bithorax mutation by ablating muscle fiber 5 in living, dechorionated stage 15-16 embryos, a time prior to the formation of synaptic contacts (Johansen et al., 1989b). The embryos were then allowed to develop to third instar larvae $(n=15$ ablated muscle 5 hemisegments in 15 embryos). We observed that $66 \%$ of the laser-treated hemisegments $(n=10)$ had ectopic endings on either muscle fiber 12 or 4 . No ectopic endings were detected on the other muscle fibers of the hemisegment. Of the ectopically placed endings, $80 \%(n=8)$ were located on muscle fiber 12 , a frequency similar to the $83 \%$ obtained following loss of muscle fiber 5 in the bithorax mutation. Figure 10 shows an example of an ectopic ending on muscle fiber 12 (arrowhead), following laser ablation of muscle fiber 5 in segment A3. The ectopic endings were similar in both location and morphology to those arising on muscle fiber 12 in bithorax larvae. Also, as was observed in the bithorax mutants, the native endings had apparently normal morphology in the laser-treated animals (arrow).

\section{Discussion}

In this study, we have examined the consequence of deleting a specific muscle fiber from the segmental body wall of Drosophila. The deletions were designed so that the innervating motoneurons were denied their normal targets. When muscle fiber 5 is deleted from a hemisegment either genetically or by means of laser lesioning, an ectopically placed ending can be found on either of two muscle fibers, 12 or 4 , that lie adjacent to the missing muscle fiber. These endings possess many features associated with physiologically normal neuromuscular contacts, including bouton morphology, transmitter phenotype, and the ability to induce glutamate sensitivity in the subsynaptic regions. The native and ectopic motor endings act independently on the

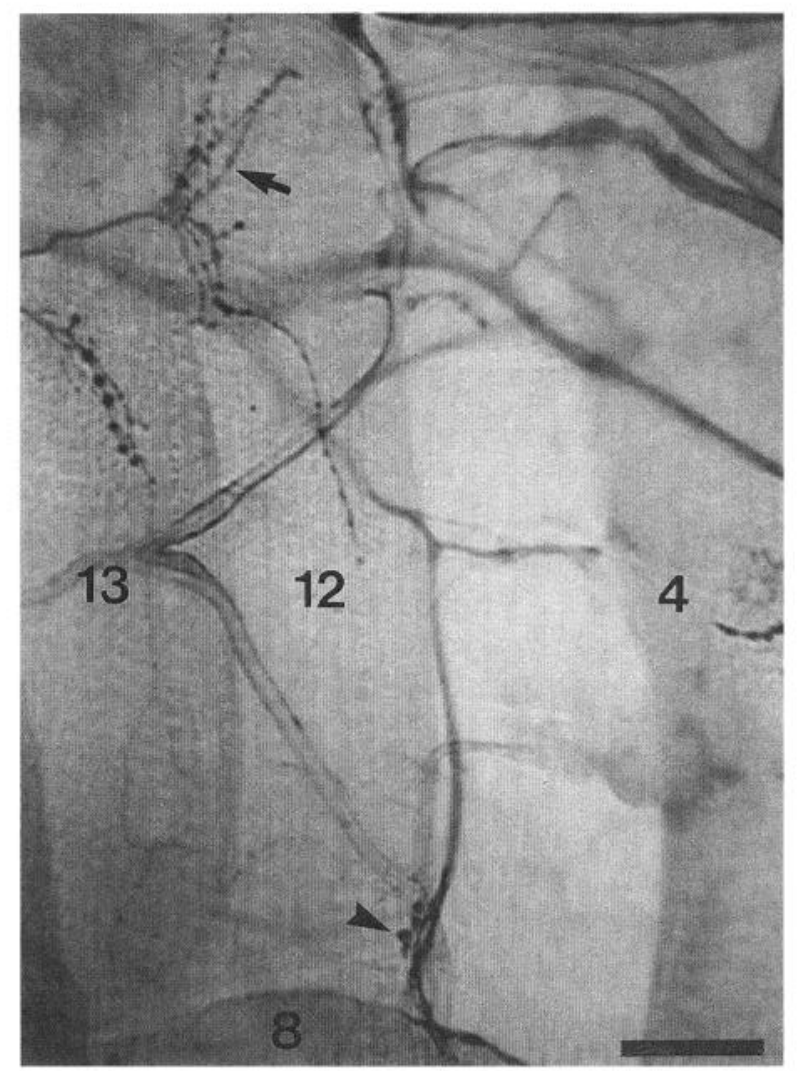

Figure 10. An ectopic muscle fiber 12 ending (arrowhead) in a third instar larva, located on the lateral surface of muscle fiber 12 in hemisegment A3. Muscle fiber 5 was deleted by laser lesioning in a stage 15/ 16 embryo, prior to synapse formation. The native ending on 12 (arrow) exhibits both normal morphology and positioning on the anterior medial surface. Anti-HRP immunocytochemistry with peroxidase reaction. Scale bar, $50 \mu \mathrm{m}$.

muscle fibers, as there were no systematic changes in the numbers of boutons and branches of the native junction despite the presence of an additional foreign contact.

\section{Homeotic transformation of muscle fibers}

The homeotic selector genes of the BX-C control the specification of segmental identity in the thoracic and abdominal segments (Lewis, 1978; Bender et al., 1983; Ghysen et al., 1985; Teugels and Ghysen, 1985; Ghysen and Lewis, 1986). Mutations in the Ubx region of BX-C affect segmental identity in the region from the posterior compartment of T2 to the anterior compartment of A1. For example, in adult flies of the genotype $a b x$ $p b x b x^{3} / P 2$, where there is a strong loss of function of $\mathrm{Ubx}$, the metathoracic halteres are transformed into mesothoracic wings. A similar transformation of the CNS toward the mesothorax is observed in this genotype (Koto et al., 1981; Thomas and Wyman, 1984; Ghysen et al., 1985). In the mesoderm, loss of function in Ubx also results in homeotic transformation of the musculature toward the mesothorax (Jan and Jan, 1981; Hooper, 1986). The transformations occur in multiple abdominal segments (Hooper, 1986), with the segmental transformation occurring as far posterior as A6 (Fig. 5).

We observed apparently normal motor innervation following homeosis, except at the site where muscle fiber 5 was absent. Rather than major errors in muscle fiber innervation, we found that the motor endings on the appropriate, intact fibers were 
Figure 11. Schematic diagram illustrating the behavior of the muscle fiber 5 motor endings (arrowheads) when the muscle fiber is present (wild type) or when they innervate ectopically muscle fiber 12 (experimental) due to either homeotic loss or laser ablation of muscle fiber 5 . In the experimental situation, the motor endings are found ectopically on muscle fiber 12 in half of the homeotically transformed hemisegments examined in segment $A 2$, and in $37 \%$ overall in segments Al-A4. The site innervated usually corresponds positionally to the native innervation site on muscle fiber 5 , transposed to the alternate target.

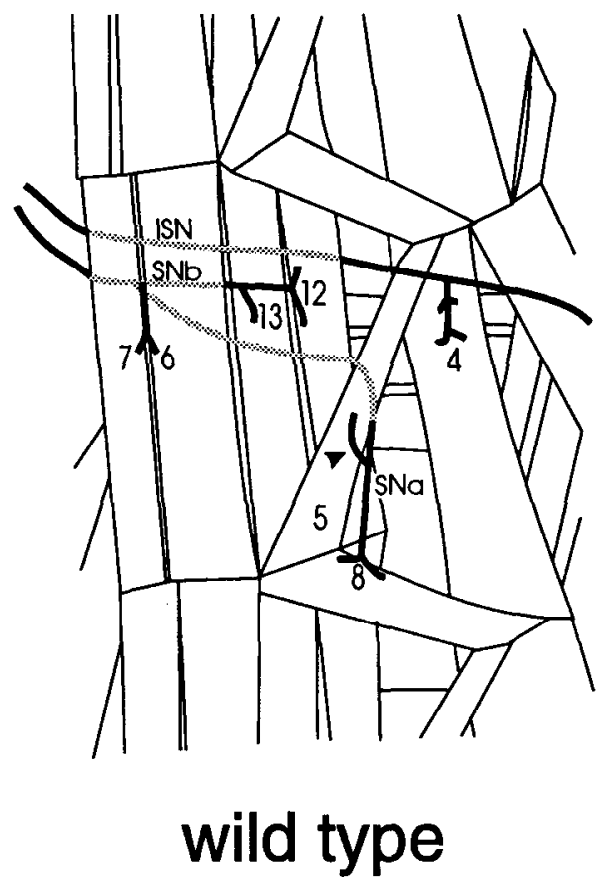

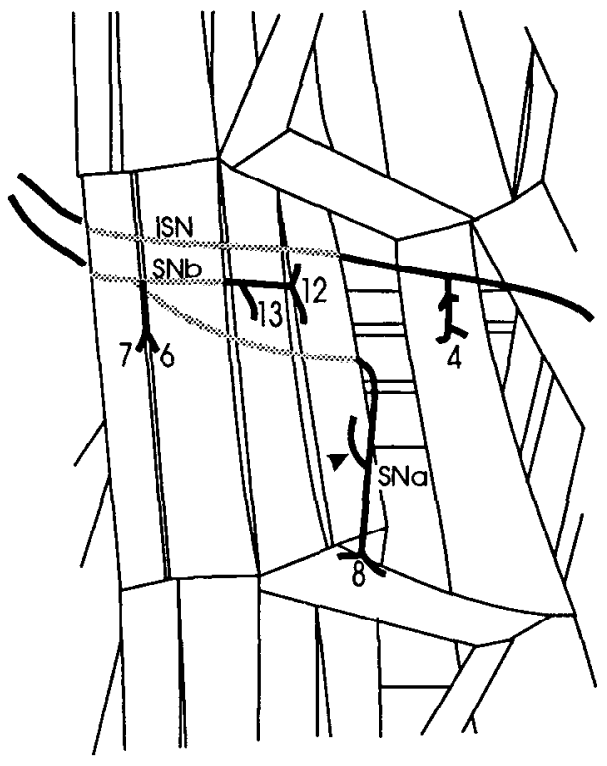

experimental morphologically normal. An explanation for this is the broad intersegmental homology in both the CNS and periphery of Drosophila embryos and larvae. The pattern of connectivity between identified motoneurons and muscle fibers is highly conserved between segments (Halpern et al., 1991; Sink and Whitington, 1991a). Thus, segmental transformation of either a motoneuron or muscle fiber by homeosis would not be expected to alter connectivity, except where the change results in the deletion or duplication of a cell.

We also uscd direct laser lesioning methods to examine alternate target choices, in order to confirm the observations made using genetic methods. This approach yielded a smaller data set ( $n=15$ hemisegments for laser ablation vs. 228 for homeosis). The results were essentially the same for both approaches. This indicates that the features we have characterized in the homeotically transformed hemisegments are likely the direct consequences of the loss of muscle fiber 5 .

\section{Behavior of displaced motor axons}

The evidence supports the hypothesis that the ectopic ending on muscle fibers 12 or 4 is made by the muscle fiber 5 motoneurons. The ectopic ending on muscle fiber 12 resembles the normal muscle 5 contact in several ways. The number of synaptic boutons and neuritic branches is similar for both cases. Also, ectopically placed type II processes are found on muscle fiber 12 at approximatcly the same rate as they appear on muscle fiber 5. Dyefills show that the type I and II endings correspond to separate neurons, with the latter derived from a motoneuron that can coinnervate muscle fiber 8 (Fig. 2C). It is possible, therefore, that the type II ectopic endings observed on muscle fiber 12 are derived from that motoneuron and are made as a consequence of the absence of muscle fiber 5 .

Alternate targets may be selected by proximity. The site selected by the displaced motoneurons was generally the muscle fiber surface closest to the missing target (Fig. 11). This suggests that muscle fiber 5 motoneurons projected normally to the posterior-pleural region of the segment despite the absence of their native target, and only then innervated muscle fibers 12 or 4 . Thus, in some cases guidance cues other than the target are capable of directing motoneuronal growth cones to specific regions of the body wall, and this guidance may also influence the choice of innervation site on the muscle fibers. These observations resemble those of Whitington and Seifert (1984), Whitington (1985), and Nässel et al. (1986), who have shown that insect motoneurons deprived of their normal muscle targets can make functional synapses on alternate foreign muscles, and often find them by tracking on preexisting nerves.

When Drosophila motoneurons differentiate their neuromuscular endings, their growth cone processes can transiently contact muscle fibers other than their final targets (Halpern et al., 1991; Sink and Whitington, 1991b). It is therefore possible that the surface of muscle fiber 12 where we observe ectopic endings is transiently contacted as the muscle fiber 5 innervation develops. This could explain why muscle fiber 12 is a preferred alternate target for the motoneurons when muscle fiber 5 is absent.

Neurons behave autonomously at the target muscle fiber. Our observations suggest that the differentiation and maturation of neuromuscular endings are shaped in part by features intrinsic to the motoneuron. The data indicate that Drosophila motoneurons do not compete for synaptic sites, or strongly influence each other's development. The ectopically placed synapses probably were also able to excite the muscle fiber. Evidence for functional synapses included the detection of neurotransmitter immunoreactivity at the boutons, and the observation of iontophoretic glutamate sensitivity at the subsynaptic region. This implies that the normal development of the native motoneurons occurred despite additional synaptic excitation from a foreign motoneuron.

The normal coexistence of multiple functional motoneuron inputs on a single Drosophila muscle fiber is dissimilar to the situation at many vertebrate neuromuscular junctions, where activity plays an important role in the regulation of neuromuscular contacts (Ridge and Betz, 1984; Thompson, 1985; Cal- 
laway et al., 1989; Lichtman and Balice-Gordon, 1990). In vertebrates, muscle fibers usually undergo synapse elimination during the early postnatal period (Redfern, 1970; Brown et al., 1976; Van Essen et al., 1990). The polyinnervating motoneurons in general occupy a common muscle fiber site (Brown et al., 1976), with the interneuronal competition strongest within the short distances that exist at a single end plate and lessening over distance (Kuffler et al., 1980; Lømo, 1980). In Drosophila, the majority of the skeletal muscle fibers are polyinnervated, with the innervating motoneurons usually arborizing at a common nerve entry point. The musculature's polyneuronal innervation arises during embryogenesis (Halpern et al., 1991; Sink and Whitington, 1991a) and persists to the third instar, as was demonstrated by the characterization of multiple neurotransmitter phenotypes at motor endings (Anderson et al., 1988; Johansen et al., 1989b), cell body backfills (Sink and Whitington, 1991a), and direct impalement of larval motor endings (present study).

The evidence thus indicates that synaptic competition and elimination are not a widespread phenomenon at Drosophila skeletal muscle fibers, even for motoneurons lying in close proximity at a common innervation site. The apparent independent behavior of Drosophila motoneurons resembles that of primary motoneurons in the zebrafish embryo (Eisen et al., 1986, 1989; Liu and Westerfield, 1991). In that system, primary motoneurons are capable of differentiating at their target muscles with mechanisms that are independent of competitive interactions and activity.

A complementary study (Chiba and Keshishian, 1991; A. Chiba, unpublished observations) also shows that Drosophila motoneurons act autonomously when innervating their muscle fiber targets during embryogenesis. For a motoneuron that innervates two adjacent muscle fibers, halving the number of targets by genetic or laser lesioning methods does not alter that neuron's innervation of the remaining targets. Similarly, motoneurons respond to a duplication of their target muscle fiber by making duplicate endings on both cells, with motoneurons projecting to adjacent muscle fibers unaffected by the duplication (Chiba and Keshishian, 1991).

In conclusion, we have found that motoneurons in Drosophila are capable of establishing stable, ectopically placed synapses when denied their normal muscle fiber targets. The cellular mechanisms that govern the specific preference of a Drosophila motoneuron for a single muscle fiber remain to be ascertained, but these results show that motoneurons can act independently of other motoneurons when innervating targets, with the behavior of the motoneuron at the target driven at least in part by intrinsic properties. Also, the motoneuronal contact appears to control the localization of the transmitter receptor. The results show that motoneurons can project to the vicinity of the target in the absence of the muscle fiber, and that the path taken by the motoneuron to the target is significant in determining the site of innervation on the muscle fiber. Collectively, these results suggest that competition is not a dominant mechanism for shaping connectivity in this system.

\section{References}

Anderson MS, Halpern ME, Keshishian HS (1988) Identification of the neuropeptide transmitter proctolin in Drosophila larvae. Characterization of muscle fiber-specific neuromuscular endings. J Neurosci 8:242-255.

Bender W, Akam M, Karch F, Beachy PA, Peifer M, Spierer P, Lewis EB, Hogness DS (1983) Molecular genetics of the bithorax complex in Drosophila melanogaster. Science 221:23-29.
Brown MC, Jansen JKS, Van Essen DC (1976) Polyneuronal innervation of skeletal muscle in new-born rats and its elimination during maturation. J Physiol (Lond) 261:387-422.

Budnik V, Zhong Y, Wu C-F (1990) Morphological plasticity of motor axons in Drosophila mutants with altered excitability. J Neurosci 10: 3754-3768.

Callaway EM, Soha JM, Van Essen DC (1989) Differential loss of neuromuscular connections according to the activity level and spinal position of neuronal rat soleus motor neurons. J Neurosci 9:18061824.

Campos-Ortega JA, Hartenstein V (1985) The embryonic development of Drosophila melanogaster. Bcrlin: Springer.

Cash S, Keshishian H (1990) Alternative neuromuscular target selection in Drosophila larvae transformed by hometoic selection. Soc Neurosci Abstr 16:302.

Chiba A, Keshishian H (1991) Growth cone choices of Drosophila motoneurons in response to mismatched targets. Soc Neurosci Abstr $17: 213$.

Crossley CA (1978) The morphology and development of the Drosophila muscular system. In: The genetics and biology of Drosophila, Vol 2b (Ashburner M, Wright TRF, eds), pp 499-560. New York: Academic.

Eisen JS, Myers PZ, Westerfield M (1986) Pathway selection by growth cones of identified motoneurons in live zebrafish. Nature 320:269271.

Eisen JS, Pike S, Debu B (1989) The growth concs of identified motoneurons in embryonic zebrafish select appropriate pathways in the absence of specific cellular interactions. Neuron 2:1097-1104.

Ghysen A, Lewis EB (1986) The function of bithorax genes in the abdominal nervous system of Drosophila. Rouxs Arch Dev Biol 195 203-209.

Ghysen A, Jan LY, Jan YN (1985) Segmental determination in Drosophila central nervous system. Cell 40:943-948.

Halpern ME, Chiba A, Johansen J, Keshishian H (1991) Growth cone behavior underlying the development of stereotypic synaptic connections in Drosophila embryos. J Neurosci 11:3227-3238.

Hooper JE (1986) Homeotic gene function in the muscles of Drosophila larvae. EMBO J 5:2321-2329.

Jan LY, Jan YN (1976a) Properties of the larval neuromuscular junction in Drosophila melanogaster. J Physiol (Lond) 262:189-214.

Jan LY, Jan YN (1976b) L-Glutamate as excitatory transmitter at the Drosophila larval neuromuscular junction. J Physiol (Lond) 262:215236.

Jan LY, Jan YN (1981) Mutations of the synapse in Drosophila. In: Development in the nervous system (Barrod DR, Feldman JD, eds), London: Cambridge University Press.

Jan LY, Jan YN (1982) Antibodies to horseradish peroxidase as specific neuronal markers in Drosophila and grasshopper embryos. Proc Natl Acad Sci USA 79:2700-2704.

Johansen J, Halpern ME, Johansen KM, Keshishian H (1989a) Stereotypic morphology of glutamatergic synapses on identified muscle cells of Drosophila larvae. J Neurosci 9:710-725.

Johansen J, Halpern ME, Keshishian H (1989b) Axonal guidance and the development of muscle fiber-specific innervation in Drosophila embryos. J Neurosci 9:4318-4332.

Koto M, Tanouye MA, Ferrús A, Thomas JB, Wyman RJ (1981) The morphology of the cervical giant fiber neuron of Drosophila. Brain Res 221:213-217.

Kuffler DP, Thompson W, Jansen JKS (1980) The fate of foreign endplates in cross-innervated rat soleus muscle. Proc R Soc Lond [Biol] 208:189-222.

Lewis EB (1978) A gene complex controlling segmentation in Drosophila. Nature 276:565-570.

Lichtman JW, Balice-Gordon R (1990) Understanding synaptic competition in theory and practice. $J$ Neurobiol 21:99-106.

Liu DWC, Westerfield M (1990) The formation of terminal fields in the absence of competitive interactions among primary motoneurons in the zebrafish. J Neurosci 10:3947-3959.

Lømo T (1980) What controls the development of neuromuscular junctions? Trends Neurosci 3:126-129.

Masinovski B, Kempf SC, Callaway JC, Willows AOD (1988) Monoclonal antibodies to the molluscan small cardioactive peptide $\mathrm{SCP}_{\mathbf{B}}$ immunolabeling of neurons in diverse invertebrates. J Comp Neurol 273:500-512.

Nässel DR, Helgee A, Sivasubramanian P (1986) Development of 
axon paths of motorneurons after removal of target muscles in a holometabolous insect. Dev Brain Res 26:211-219.

Redfern PA (1970) Neuromuscular transmission in newborn rats. J Physiol (Lond) 209:701-709.

Ridge RMAP, Betz WJ (1984) The effect of selective chronic stimulation on motor unit size in developing rat muscle. J Neurosci 4: 2614-2620.

Sink H, Whitington PM (199 la) Location and connectivity of abdominal motorneurons in the embryo and larva of Drosophila melanogaster. J Neurobiol 22:298-311.

Sink H, Whitington PM (1991b) Pathfinding in the central nervous system and periphery by identified embryonic Drosophila motor axons. Development 112:307-316.

Teugels E, Ghysen A (1985) Independence of the number of legs and leg ganglia in Drosophila bithorax mutants. Nature 314:558-561.

Thomas JB, Wyman RJ (1984) Duplicated neural structure in bithorax mutant Drosophila. Dev Biol 102:531-533.
Thomas JB, Bastiani MJ, Bate M, Goodman CS (1984) From grasshopper to Drosophila: a common plan for neuronal development Nature 310:203-207.

Thompson WJ (1985) Activity and synapse elimination at the neuromuscular junction. Cell Mol Neurobiol 5:167-182.

Van Essen DC, Gordon H, Soha JM, Fraser SE (1990) Synaptic dynamics at the neuromuscular junction: mechanisms and models. $J$ Neurobiol 21:223-249.

Whitington PM (1985) Functional connections with foreign muscles made by a target deprived insect motorneuron. Dev Biol 107:537540 .

Whitington PM, Seifert E (1984) Axon growth from limb motorneurons in the locust embryo: the effect of target limb removal on the pattern of axon branching in the periphery. Dev Biol 106:438-449. 